\title{
MODAL AND FLUTTER ANALYSIS OF THE SAILPLANE LAK-17B USING NUMERICAL METHODS
}

\author{
Marius Andrikaitis, Algimantas Fedaravičius \\ Dept of Transport Engineering, Kaunas University of Technology, Lithuania
}

Submitted 10 May 2013; accepted 1 January 2014

\begin{abstract}
The objective of current work is to determine the $V-g$ and $V-f$ diagrams for the sailplane's LAK-17B empennage using numerical methods. The article considers the following problems: development of finite element model of the sailplane LAK-17B; normal modes calculation using created finite element model; flutter analysis of sailplane LAK-17B using doublet lattice method.
\end{abstract}

Keywords: sailplane, finite element model, flutter, normal modes, simulation.

Reference to this paper should be made as follows: Andrikaitis, M.; Fedaravičius, F. 2014. Modal and flutter analysis of LAK-17B sailplane using numerical methods, Transport 29(1): 84-89. http://dx.doi.org/10.3846/16484142.2014.898217

\section{Introduction}

The Doublet-Lattice Method (DLM) is widely used for subsonic unsteady aerodynamic aircraft modelling (Chipman, Rauch 1975; Hollmann 1991; Vittala et al. 2008, 2010).

Chipman and Rauch (1975) analysed the effect on flutter of the aerodynamic interaction between the space shuttle bodies and wing. DLM combined with slender body theory to calculate unsteady aerodynamic forces, was used to compute subsonic flutter speeds for comparison with test results of scale semi span models of the orbiter wing, the complete shuttle and intermediate component combinations.

Hollmann (1991) made a series of studies to predict critical flutter speeds of light aircraft structures. Several different cases were considered: preliminary aircraft design, certification, crash due to low-speed empennage flutter investigation. In all cases doublet lattice method was demonstrated to be reliable.

Vittala et al. (2010) presented dynamic and aero elastic characteristics simulation of a composite light aircraft using MSC.Nastran code and typical section method. Correlation of dynamic characteristics of aircraft with results obtained from ground vibration test of aircraft was studied. Critical flutter, divergence and control reversal velocities of complete aircraft were computed. Close agreement was observed between computational and experimental frequencies.
The purpose of current work is to determine the diagrams of damping and frequency versus flight speed for the empennage vibration modes of the sailplane LAK-17B. These types of diagrams are used to determine critical flutter speeds of the aircraft (Vittala et al. 2008) and to investigate the flutter mechanisms (Hollmann 1991) as well.

The LAK-17B is a modification of the sailplane LAK-17A. It is a single seat all-composite sailplane of FAI $15 \mathrm{~m}-18 \mathrm{~m}$ class. During the ground vibration testing it was found that the fuselage twisting mode and 1st asymmetric wing bending mode have close natural frequencies (Rugaitis et al. 2010), similar to the earlier version - LAK-17A. The flutter behaviour of these modes is further investigated in this paper.

The analyses were performed for two configurations, corresponding to two wingspans of the sailplane. For each configuration, two conditions were simulated:

- rudder fixed;

- rudder free.

The rudder control system is of combined type: steel cable from pedals to a bell crank in the middle part of fuselage and steel rod from the bell crank till the rudder.

The flutter analysis procedure that is chosen in this work consist of the following sequential steps:

- finite element modelling;

- validation of the finite element models;

- flutter analysis using created models. 
A wing, tail, fuselage and control systems of the sailplane were modelled using finite element modelling software. Two types of models were created: structural and aerodynamic.

Dynamic analyses were performed using created structural models. The models were validated by comparing numerically obtained natural frequencies to experimental data.

The aerodynamic and structural finite element models were created using MSC.Patran pre-processor. Infinite plate splines were used to interpolate between aerodynamic and structural displacements (MSC Software Corporation 2005). Natural frequencies spectrum of complete sailplane has been obtained by invoking Lanczos method in MSC.Nastran code. For flutter solutions, PK method of MSC.Nastran was used (MSC Software Corporation 2005).

\section{Finite Element Model}

\subsection{Airframe}

The Finite Element Models (FEM) of airframe parts were created using Quad4 and Tria3 shell elements of MSC.Nastran (MSC Software Corporation 2005). The following procedures were used to generate finite element mesh (Fig. 1):

- surfaces generation;

- mesh seeding;

- meshing;

- equivalencing.

During first modelling stage, the complete sailplane was modelled as a collection of bi-parametric topologically congruent surfaces. That is, all the adjacent surfaces shared a common edge. Surfaces were generated using 3D CAD modelling software.

Two types of mesh seeds were used to control model's mesh transition. Two-way bias seeds were used in chord-wise direction of aerodynamic surfaces to concentrate the element nodes near the leading edges and spars. The uniform mesh seeds were used in span-wise direction of aerodynamic surfaces and for the whole fuselage as well.
Automatic mesh generation tools of FEM preprocessor were used to mesh each individual surfaces of geometric model.

At equivalencing process, all the nodes that coexisted at a point were reduced to a single node. Equivalencing tolerance of $0.5 \mathrm{~mm}$ was used. The meshes that represent different parts were prevented from automatic nodes equivalencing by using minimal distance of $2 \mathrm{~mm}$ between these parts nodes.

After creating the meshes and applying composite material properties, finite element model stiffness was verified using experimental data (Andrikaitis, Fedaravičius 2012).

\subsection{Connections of Parts}

The meshes that represent different parts of the sailplane were connected to each other using Multi-Point Constraints (MPCs) and beam elements.

Fig. 2 shows an example of how the hinges connecting rudder to the vertical tail plane were modelled.

The hinge is represented as a one-dimensional beam element (position 1) with two nodes (position 2, position 3). Rotational behaviour of the hinge is mod-

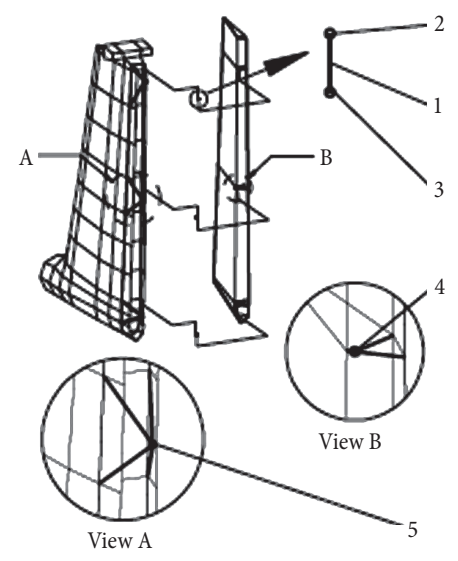

Fig. 2. Modelling of control surfaces hinges: 1 - beam element; 2,3 - nodes of the beam element; 4, 5 - multipoint constraints

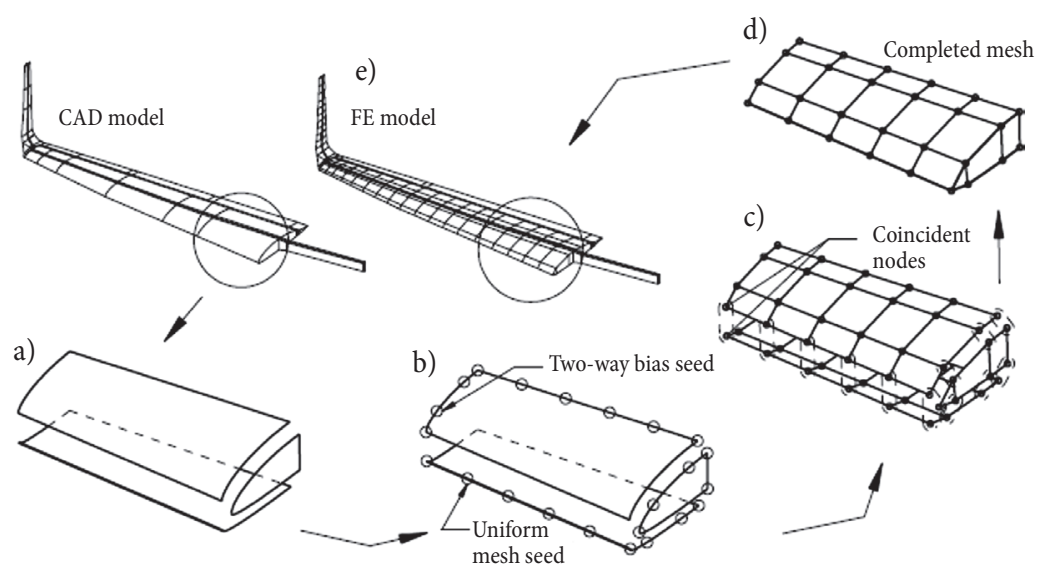

Fig. 1. The airframe modelling stages (shown on $15 \mathrm{~m}$ outer wing): a - surfaces generation; $\mathrm{b}$ - mesh seeding; $\mathrm{c}$ - meshing; $\mathrm{d}$ - equivalencing; $\mathrm{e}$ - finished mesh 
elled by removing these nodes' rotational degrees of freedom around beam element's longitudinal axis from stiffness calculations.

Beam element's nodes are connected to rudder and fin meshes using MPCs (position 4, position 5). elements.

Control system linkages were modelled using beam

\subsection{Control Surfaces Balance}

The static moment of a real control surface is checked by measuring a component $P$ of weight and the distance $r$ between rotation axis and weighing point (Fig. 3a). Then, a static moment of a control is calculated as follows:

$$
M=P \cdot r,
$$

where: $M$ - static moment; $P$ - component of weight at a weighing point; $r$ - static moment arm.

The Finite Element (FE) models of control surfaces were modified by adding lumped masses at the front and the back of the surface (Fig. 3b). Thus, the modelled and real control surfaces had the same static moments.

Front weight correction was calculated using equation:

$$
G_{F}=\frac{G_{m} \cdot x_{G}+L_{B} \cdot\left(G-G_{m}\right)-r \cdot P}{L_{F}+L_{B}}
$$

where: $G$ - control surface weight; $r$ - static moment arm; $P$ - reaction force; $G_{F}$ - front weight correction; $G_{m}$ - FE model weight; $L_{F}, x_{G}, L_{B}$ - distances between pivot point and concentrated weights.

After calculation of front weight correction, back weight correction is found as follows:

$$
G_{B}=G-G_{m}-G_{F},
$$

where: $G$ - control surface weight; $G_{m}$ - FE model weight; $G_{F}$ - front weight correction; $G$ - control surface weight.

\subsection{Airframe Mass Distribution}

After creating the meshes of the airframe parts and applying material properties, the initial mass of the model was $m_{M}$. That mass was modified to reflect the mass of an actual sailplane $m_{S}$ by adding corrective masses $m_{C}$ to the model.

Fig. 4 represents the mass correction procedure used for the fuselage model. The same procedure was applied to all the modelled parts of the airframe.

Theoretical mass distribution was known - the fuselage was determined as a beam with attached masses $m_{i}$. These masses were reduced by subtracting fuselage model mass $m_{M}$ :

$$
m_{C}=\sum_{i=1}^{n} m_{C_{i}}=\sum_{i=1}^{n}\left(m_{i}-\frac{m_{i} \cdot m_{M}}{m_{\text {fuselage }}}\right),
$$

where: $m_{C}$ - corrective mass; $m_{i}$ - fuselage segment mass; $m_{M}$ - model mass; $m_{\text {fuselage }}-$ fuselage mass; $n$ number of corrective masses.

The calculated corrective masses $m_{C_{i}}$ were distributed at corresponding sections of the fuselage finite element model as shown at Fig. 4. a)

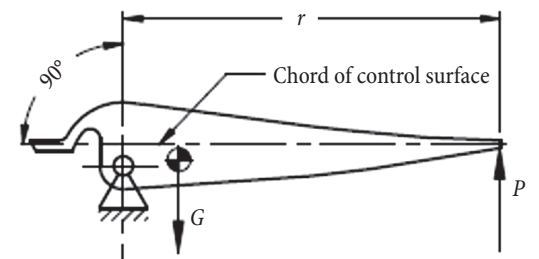

b)

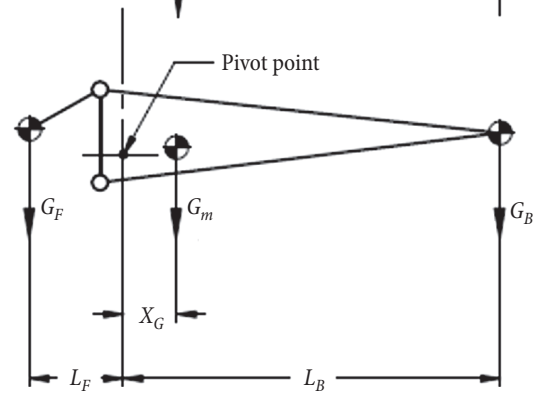

Fig. 3. Modelling of control surfaces: a - real control surface; $\mathrm{b}$ - finite element model

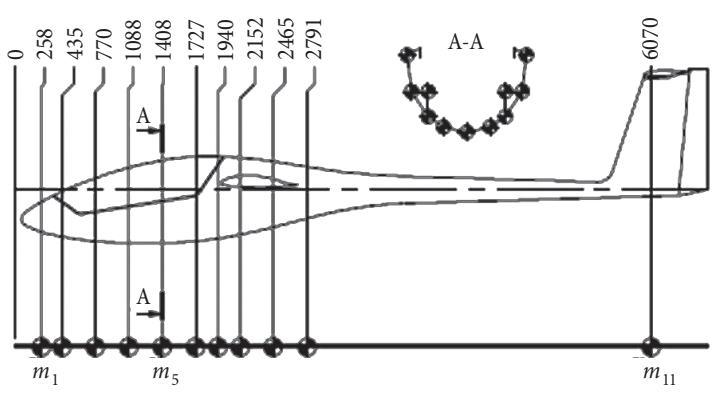

Fig. 4. Fuselage mass correction

\subsection{Aerodynamic Model}

Lifting surfaces of the sailplane were modelled as a collection of flat panels (Fig. 5). Each panel was divided into elements. The following guidelines were observed in subdivision (Hollmann 1991):

- the dimensions of elements should be decreased in the directions and regions of large gradients in pressure and/or downwash;

- the aspect ratio of each element should be less than or equal to 1 .

Other researchers have found that inclusion of slender bodies and interference elements in aerodynamic models increases calculated flutter velocity marginally (Vittala et al. 2010). Therefore, the fuselage of the sailplane was not modelled.

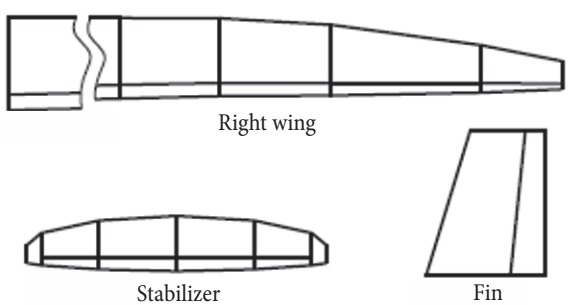

Fig. 5. Aerodynamic models of sailplane lifting surfaces 


\section{Normal Modes Calculation}

The normal modes calculations were carried out for two sailplane configurations:

- wing span of $15 \mathrm{~m}$;

- wing span of $18 \mathrm{~m}$.

The results are shown at the Table. Calculated frequencies are compared to corresponding frequencies measured during Ground Vibration Tests (GVT). Currently, only the $18 \mathrm{~m}$ sailplane test results are available. The comparison between measured and computed frequencies confirmed the adequacy of mass and stiffness models, however, it should be noted that the numerically obtained frequencies of symmetric modes correspond to experimentally measured frequencies better than asymmetric wing and fuselage frequencies. The following reasons of results inconsistency were considered:

- inadequate fuselage moments of inertia due to simplified mass correction procedure described at this paper (non-structural masses, as pilot and equipment were distributed on airframe shell structure);

- different simulation and test conditions; during simulation, the model was unsupported; during GVT, the sailplane was supported at its Centre of Gravity (CG) by springs.

Those hypotheses will be tested at future work. Currently, the calculated results are considered acceptable.

Two calculated modes of $18 \mathrm{~m}$ wing span configuration had similar resonant frequencies: wing 2 nd asymmetric bending $(4.59 \mathrm{~Hz})$ and fuselage torsion $(3.94 \mathrm{~Hz})$. Rudder flapping frequency depends on velocity, there-

Table. Sailplane LAK-17B normal modes: theoretical and experimental data

\begin{tabular}{lcc|c}
\hline \multirow{2}{*}{ Oscillation form } & \multicolumn{3}{c}{ Frequency, (Hz) } \\
\cline { 2 - 4 } & \multicolumn{2}{c}{$18 \mathrm{~m}$} & $15 \mathrm{~m}$ \\
\cline { 2 - 4 } & FEA & GVT & FEA \\
\hline Wing 1st symmetric bending & 1.79 & 1.52 & 2.57 \\
\hline Wing 2nd symmetric bending & 6.18 & 6.07 & 10.44 \\
\hline Wing 3rd symmetric bending & 14.77 & 14.65 & 18.36 \\
\hline Wing 4th symmetric bending & 25.35 & 22.86 & - \\
\hline Wing 1st asymmetric bending & 4.59 & 4.15 & 7.09 \\
\hline Wing 2nd asymmetric bending & 10.86 & 14.58 & 13.81 \\
\hline Wing 3rd asymmetric bending & 22.41 & 22.3 & 28.20 \\
\hline Wing torsion & 18.73 & 20.01 & 21.86 \\
\hline Fuselage bending in horizontal plane & 8.49 & 10.98 & 8.68 \\
\hline Fuselage bending in vertical plane & 9.25 & 11.23 & 9.03 \\
\hline Rudder flapping & 0.05 & - & 0.05 \\
\hline Fuselage torsion & 3.94 & 4.12 & 4.26 \\
\hline
\end{tabular}

Notes:

FEA - Finite Element Analysis;

GVT - Ground Vibration Test

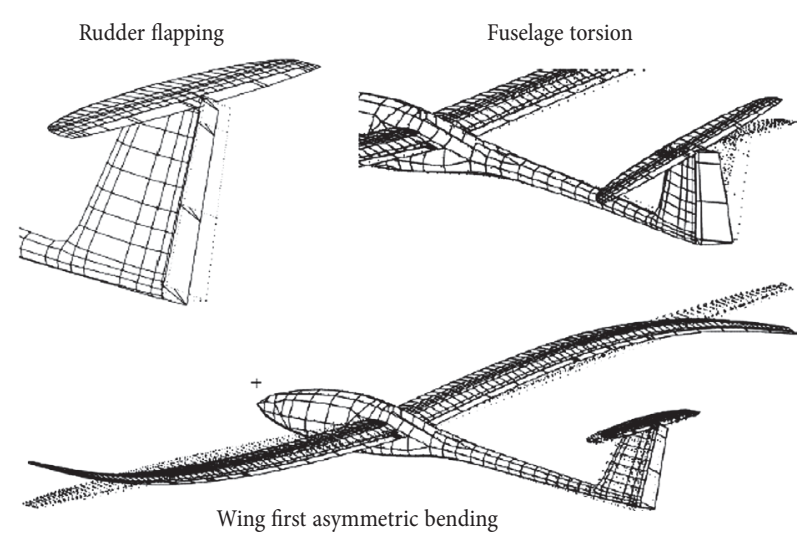

Fig. 6. Sailplane LAK-17B normal modes of interest

fore, at certain flight speeds it might match the wing or fuselage frequencies as well.

These modes (Fig. 6) were selected for further empennage flutter analysis.

\section{Flutter Analysis}

The analyses were performed for two configurations, corresponding to two wingspans of the sailplane:

- wing span of $15 \mathrm{~m}$;

- wing span of $18 \mathrm{~m}$.

For each configuration, two conditions were simulated:

- rudder fixed;

- rudder free.

In all cases, the inherent damping of sailplane structure was neglected.

The flutter analysis was carried out for all the mode shapes of the sailplane up to frequency of $30 \mathrm{~Hz}$ in velocity range of $50 \div 450 \mathrm{~km} / \mathrm{h}$.

Fig. 7 shows the damping and frequency plots for rudder flapping, wing 2 nd asymmetric bending and fuselage torsion of the sailplane with $15 \mathrm{~m}$ wing span. The results of $18 \mathrm{~m}$ configuration is shown at Fig. 8 .

When rudder is free, fuselage torsion modes crosses the zero damping line in the $V-g$ diagrams at $80 \mathrm{~km} / \mathrm{h}$ and crosses back over at $150 \mathrm{~km} / \mathrm{h}$.

When the rudder is fixed, all the modes are below zero damping line in the $V-g$ diagrams.

According to $V-f$ diagrams, reduction of damping is caused by rudder flapping and fuselage torsion modes. The curves of these modes crosses at speed range of $90 \div 120 \mathrm{~km} / \mathrm{h}$ (Fig. 9).

Reduced aerodynamic damping does not necessarily represent a flutter problem, because the inherent damping of sailplane structure was neglected at current stage of investigation and the aerodynamic models used in analyses were not validated.

The accuracy of aerodynamic models will be verified by performing dynamic aeroelastic response analyses and comparing results with test flights data. 

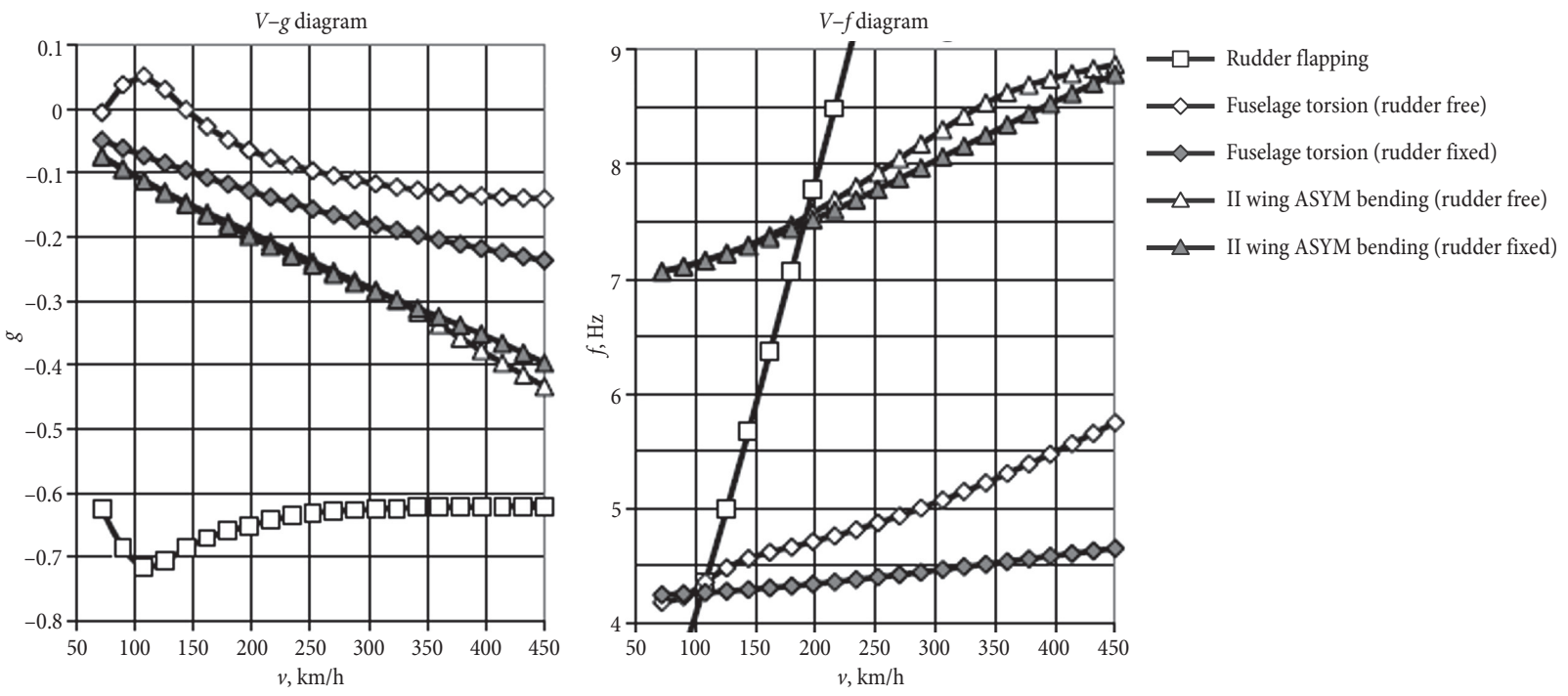

Fig. 7. $V-g$ and $V-f$ diagrams of sailplane LAK-17B with $15 \mathrm{~m}$ wing span
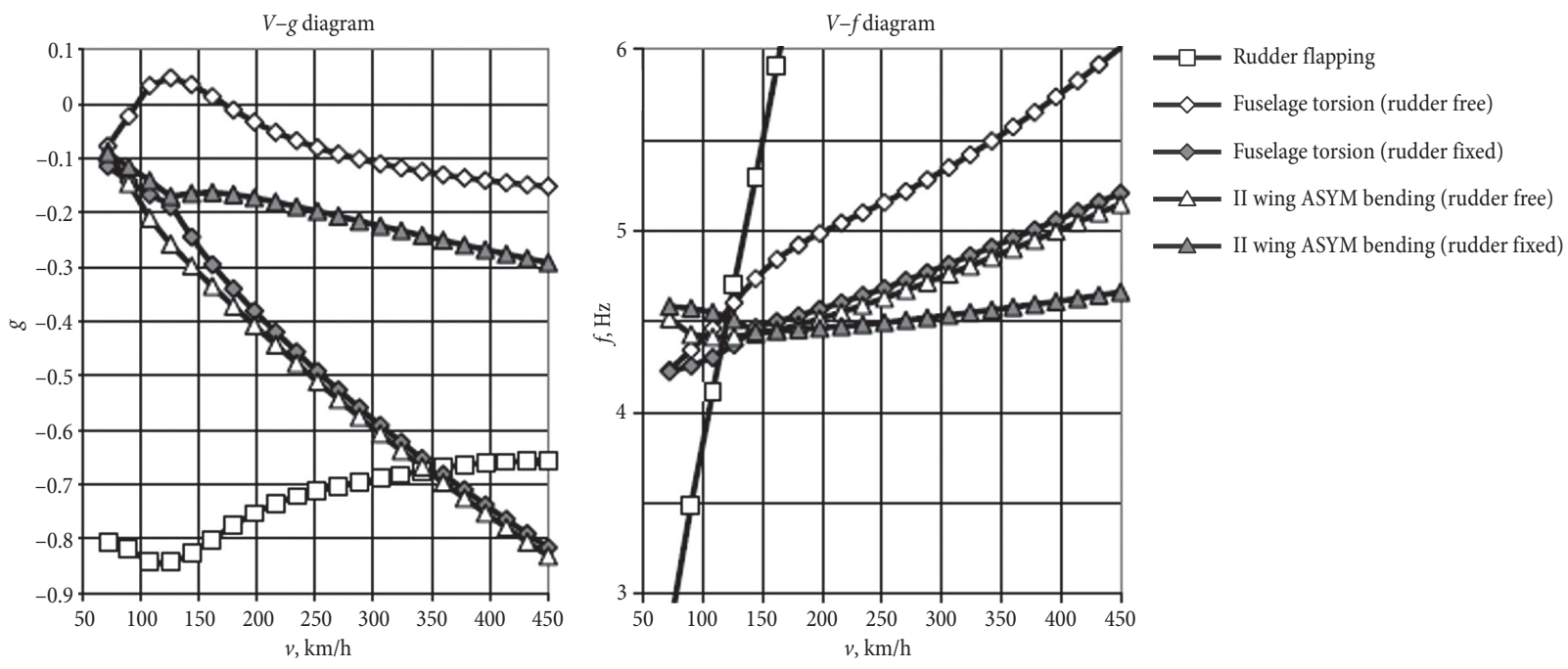

Fig. 8. $V-g$ and $V-f$ diagrams of sailplane LAK-17B with $18 \mathrm{~m}$ wing span
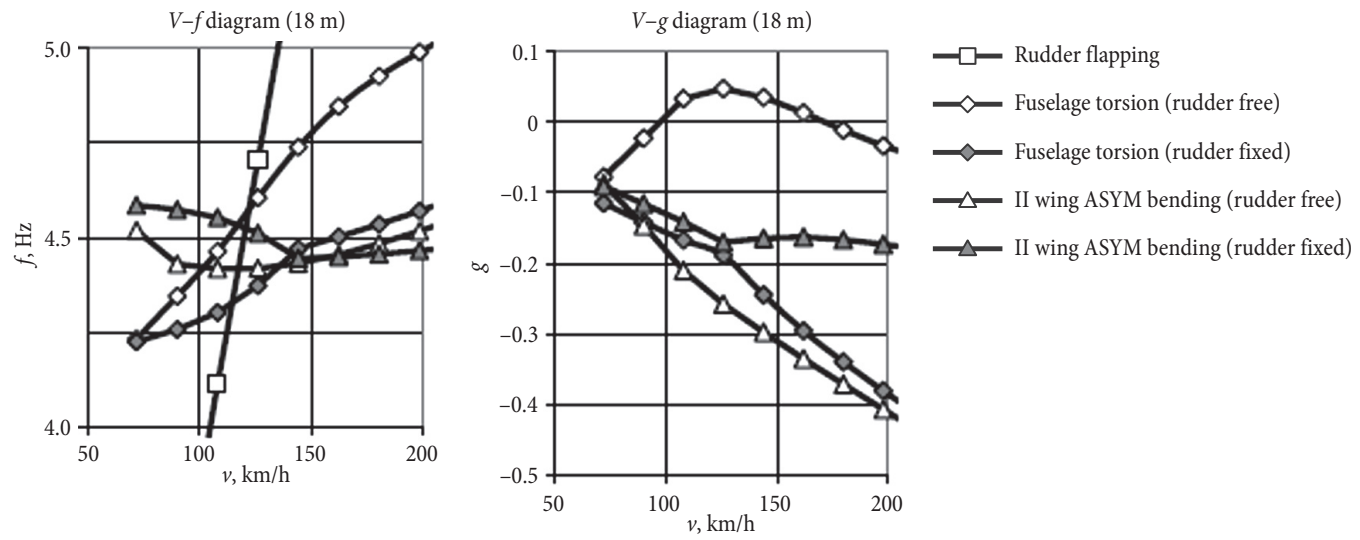

Fig. 9. Close-up view of frequency and damping plots at speed range of $50 \div 200 \mathrm{~km} / \mathrm{h}$ 


\section{Conclusions}

The purpose of this study was to determine the $V-g$ and $V-f$ diagrams for the empennage vibration modes of the sailplane LAK-17B. These diagrams are shown in Figs 7 and 8. At current stage of investigation the following conclusions were made:

1. Numerically obtained frequencies of symmetric modes correspond to experimentally measured frequencies better than asymmetric wing and fuselage frequencies. The model inertial airframe and control surfaces characteristics and boundary conditions used for simulation should be revised at future work.

2. Reduction of aerodynamic damping of the fuselage was observed in $V-g$ diagrams in the speed range of $100 \div 150 \mathrm{~km} / \mathrm{h}$ when the rudder is free (pilot's feet are off the rudder pedals). Reduced aerodynamic damping does not necessarily represent a flutter problem, because the inherent damping of sailplane structure was neglected at current stage of investigation.

3. At future work, the model should be validated by performing dynamic aeroelastic response analysis and comparing results with test flights data.

\section{References}

Andrikaitis, M.; Fedaravičius, A. 2012. Development of a finite element model of the sailplane fuselage, Journal of Vibroengineering 14(3): 1390-1398.

Chipman, R. R.; Rauch, F. J. 1975. Analytical and Experimental Study of the Effect of Wing-Body Aerodynamic Interaction on Space Shuttle Subsonic Flutter. NASA contractor report NASA CR-2488. 73 p. Available from Internet: http://ntrs.nasa.gov/archive/nasa/casi.ntrs.nasa. gov/19750006743_1975006743.pdf

Hollmann, M. 1991. Modern Aerodynamic Flutter Analysis. Aircraft Designs, Inc. 160 p.

MSC Software Corporation. 2005. MSC.Nastran 2005: Release Guide. 264 p. Available from Internet: http://web.mscsoftware.com/support/prod_support/nastran/documentation/ rg_2005.pdf

Rugaitis, A; Juočas, K.; Volkovas, V.; Deksnys, V. 2010. Modeling, experimental research and critical parameter analysis of glider's dynamic characteristics, Mechanika (6): 38-42.

Vittala, N. G. V.; Pankaj, A. C.; Venkatasubramanayam, D. V. 2010. Flutter analysis of a composite light trainer aircraft, Journal of Scientific \& Industrial Research 69(2): 113-120.

Vittala, N. G. V.; Pankaj, A. C.; Swarnalatha, R. 2008. Dynamic and aeroelastic analysis of a transport aircraft, in Proceedings of the International Conference on Aerospace Science and Technology, 26-28 June 2008, Bangalore, India. Paper No INCAST 2008-057. Available from Internet: http://nalir.nal.res.in/5007/1/INCAST_2008-057.pdf 